\title{
How Do You Rate Scientific and Technical Programs for Funding Priorities, Blue Ribbon Panels for Effectiveness?
}

\section{MRS Survey Offers Materials Community Opportunity to Voice Opinions}

This first survey of opinions on issues of interest to the materials community is an experiment. The MRS BULLETIN would like to publish a summary of your responses and announce the availability of the summary to the broader technical community. We hope your response will be sufficient to justify continuing this format as a conduit for community views.

This survey solicits your views on two topics: (1) funding priorities and the relative importance of various technical and scientific programs in the United States, and (2) the use of expert "blue ribbon" committees to guide these activities. In recent years a number of such scientific or technical committees have been formed to prepare recommendations and priorities for various programs.

If your response warrants, subsequent surveys will summarize some specific programs and ask for your perceptions of their emphasis and balance. Your opinions about the efficacy of the survey idea itself can be communicated to the MRS BULLETIN in a separate letter to the editor.

You need not be a member of the Materials Research Society, live in the United States, or be a U.S. citizen to respond to this survey. The deadline for replies is December 12, 1988.

\section{Funding Priorities}

1. Rate each of the following scientific and technical programs according to how important it is that the United States support major funding to maintain and/or improve national and international quality of life and security. (Use a scale of 1 to $5 ; 1=$ highest, 5 = lowest.)

- A Acid rain

_B Agriculture, food, \& nutrition

_C Atmospheric $\mathrm{CO}_{2}$ increase

- D Atmospheric ozone depletion

_E Augmented science programs at universities

F Biological initiatives (new)

G Conventional weapons

— H Energy alternatives
- I Energy conservation

_ J Health care \& medicine

_ $\mathrm{K}$ Instrumented space exploration

_ L Manned space flight program

_ M Nuclear weapons

- N Semiconductor development

- O Solid state sciences

- P Space station

- Q Space sciences
_ $\mathbf{R}$ Strategic defense initiative

_ S Superconducting super collider

— T Superconductors

- U Synchrotron light sources (new)

_ T Technology transfer programs

W Toxic waste

_ X Transportation alternatives

_ Y Other (specify)

2. Is the current and near future federal funding of science and technology essentially constrained by a "zero sum" algorithm, i.e., that significant new programs cannot receive large increments on top of existing funding? (circle one)
Yes
No
Don't Know

3a. Which of the programs listed in question 1 might command large funding increases without affecting the funding of other science and technology efforts? (Circle as many as needed)
A B C D E F G H I J K L M N
O P
Q R S T U V W X Y

3b. Which of the programs you circled in 3a should receive significantly increased funding? (Circle subset of $3 a$ )

A B C D E F G H I J K L M N O P Q R S T U V W X Y

4. Which of the programs listed in question 1 should receive significant funding increases at the expense of other efforts in science and technology? (Circle as many as needed)

\section{A B C D E F G H I J K L M N O P Q R S T U V W X Y}

5. A future survey will deal with the support of various energy programs in the United States whose program research and supporting technology could take several directions. From your technical perspective, please prioritize the following energy areas according to their relative importance, and therefore funding, over the next ten years. (Use a scale of 1 to $10 ; 1=$ most important, $10=$ least important.)

- Coal utilization
- Conservation
- Geothermal
- Hydroelectric

- Coal utilization

- Hydroelectric

Natural gas exploration
and recovery
- Nuclear power-fission
_ Nuclear power-fusion
_ Oil exploration and recovery
_ Oil shale
_ Solar-all forms




\title{
"Blue Ribbon" Panels
}

6. The appointment of blue ribbon scientific/technical committees primarily proceeds through bodies such as the National Academies of Sciences and Engineering, the Energy Research Advisory Board, etc. Is this the most appropriate process? (circle one)
Yes
No
Don't Know

7. If not, briefly list up to three defects or drawbacks you have identified in this method.

8. Whether you answered "Yes" or "No" to question 6, can you suggest acceptable alternative procedures for forming such committees? Briefly list up to two.

9. By and large, have the reports of blue ribbon panels resulted in effective implementation of recommendations? (circle one)

$$
\text { Yes No Don't Know }
$$

10. If not, give some examples of how they may have missed the mark.

Please complete the following information about yourself:

$\begin{array}{llllll}\text { MRS Member } & \text { Yes } & \text { No } & \text { U.S. citizen } & \text { Yes } & \text { No } \\ \text { E-MRS Member } & \text { Yes } & \text { No } & \text { Live in United States } & \text { Yes } & \text { No }\end{array}$

Please type or print your responses and return these pages (or a good photocopy) by December 12, 1988 to: MRS BULLETIN Survey, 9800 McKnight Road, Suite 327, Pittsburgh, PA 15237. You can also fax your response to: (412) 367-4373.

If mailed in the U.S., fold survey so return address shows, staple closed, apply $25 \notin$ postage and mail.

\author{
MRS BULLETIN Survey \\ 9800 McKnight Road, Suite 327 \\ Pittsburgh, PA 15237
}

